\title{
DESAIN GRAFIS PENINGKATAN KEMAMPUAN MULTIMEDIA PADA REMAJA DESA SEANTIS
}

\section{Graphic Design Enhancing Multimedia Capabilities for Youth in Saentis Village}

\section{Tengku Mohd Diansyah'*}

Rachmat Aulia ${ }^{2}$

Dodi Siregar ${ }^{3}$

*IUniversitas Harapan Medan, Medan, Provinsi, Indonesia

2 Universitas Harapan Medan, Medan, Provinsi, Indonesia

3 Universitas Harapan Medan, Medan, Provinsi, Indonesia

*email: dian.10.22@gmail.com

\section{Kata Kunci:}

Multimedia

Desain Grafis

Remaja Desa

Keywords:

Multimedia

Graphic Design

Youth Village

\begin{abstract}
Abstrak
tema yang diberikan pada pelaksanaan kegiatan pengabdian masyrakat ini adalah bagaimana menigkatkan kemampuan desain grafis bagi pemuda (Remaja) di desa Seantis adapun tujuan dapat memperkenalkan, melatih dan meningkatkan keterampilan remaja mesjid dalam bidang IT khususnya bidang desain grafis melalui perancangan spanduk atau banner. Pengabdian ini bertujuan menghasilkan remaja mesjid yang memiliki bakat dan keterampilan dibidang desain grafis yang nantinya dapat digunakan untuk mendapatkan penghasilan tambahan dengan membuka usaha desain grafis seperti usaha percetakan.
\end{abstract}

\begin{abstract}
The theme in the implementation of community service activities is graphic design. Increasing the ability of multimedia in Saentis village adolescents in order to increase the ability of graphic design for youth in Seantis village. As the aim of this activity is to introduce, train and improve mosque skills in the IT field specifically in the field of graphic design through the design of banners or banners. This dedication supports the creation of young people who have talent and skills in the field of graphic design that can be used to get additional training with attractive designs such as printing business.
\end{abstract}




\section{PENDAHULUAN}

Desain grafis adalah ilmu yang mempelajari bagaimana menghadirkan media komunikasi dalam bentuk gambar menjadi lebih efektif sehingga informasi yang disampaikan dapat terlihat menarik dan nyaman pada saat dibaca. Desain grafis juga dapat diartikan Desain grafis lahir dari kebutuhan manusia akan komunikasi melalui bahasa visual sejak abad ke- 19 hingga jaman modern. Mulai dari penggunaan simbolsimbol sederhana sampai perangkat komputer yang canggih. Desain yang berakar dari senirupa murni yang kemudian berkembang menjadi fungsi identifikasi, informasi, instruksi serta Promosi dan Presentasi. Desain grafis adalah suatu media untuk menyampaikan informasi melalui bahasa komunikasi visual dalam wujud dwimatra ataupun trimatra yang melibatkan kaidah-kaidah estetik.(Dewojati, 2015) Perpaduan isi yang terdapat dalamnya meliputi text, shape, tabel, dan lain sebagainya yang dianggap sebuah gambar. Dalam memulai pembelajaran desain grafis, sesorang harus memiliki kemampuan atau skill visual dan kognitif seperti fotografi, typografi, ilustrasi, serta mampu mengelola gambar sekaligus tata letaknya. Selain itu, kemampuan desain grafis ini dapat membuat seseorang tidak hanya trampil dalam ilmu desain, tapi juga dapat dijadikan sebagai keterampilan usaha multimedia sebagai bahan persentasi materi dengan menggunakan kata-kata dan gambar (Rahmat, 20I5) sehingga Media tersebut sangat efektif dalam memberikan informasi Karena media tutorial merupakan sarana media (Ryza, Spd and Kom, 2014)

Dari analisis situasi dan observasi dilapangan, maka tim pengabdian masyarakat dapat merumuskan masalah yaitu Bagaimana meningkatkan keterampilan remaja mesjid dibidang IT yang dapat membuka peluang usaha sebagai penghasil tambahan bagi remaja di desa tersebut. Adapun tujuan diadakan kegiatan pengabdian masyarakat ini adalah untuk meningkatkan keterampilan remaja Desa Saentis dibidang desain grafis seperti membuat dan mendesain spanduk, banner.

\section{METODOLOGI}

Dalam kegiatan pengabdian masyrakat ini menggunakan tim memberikan pelatihan yang berupa workshop dalam penggunaan aplikasi multimedia seperti mendesain spanduk, dan banner kepada remaja di desa Seantis. Proses yang di lakukan agar kegiatan ini dapat adanya faktor-faktor pendukung sebelum pelaksanaan kegiatan pengabdian berlangsung. Adapun faktor-faktor pendukung pelaksanaan kegiatan pengabdian masyarakat antara lain sebagai berikut:

a) Diterimanya usulan pengabdian masyarakat ini dengan tangan terbuka oleh kepala Desa untuk memperdayakan pemuda desa dalam mengkikuti kegiatan masyarakat ini,

b) Kemauan para remaja desa Saentis untuk mengikuti kegiatan Pelatihan Desain Grafis Untuk Meningkatkan Keterampilan dalam bidang multimedia untuk meciptakan jiwa kewirausahaan di kalangan remaja Desa Saentis,

c) Adanya sarana dan prasana pendukung yang lengkap seperti audotorium balai desa berserta 20 Unit Laptop, infocus, white board, dan spidol.

\section{HASIL DAN PEMBAHASAN}

Tema kegiatan pengabdian masyarakat yang telah dilaksanakan adalah " peningkatan keahlian para pemuda desa dalam melakukan Desain Grafis Untuk bagi Remaja Desa Saentis". Kegiatan ini diikuti oleh remaja desa sebanyak 20 orang. Hasil akhir dari kegiatan pengabdian masyarakat ini adalah $80 \%$ remaja desa dapat berhasil memahami apa itu desain grafis dengan mendesain dan membuat spanduk dan banner untuk meningkatkan kreativitas nya dalam mendesain multimedia dalam hal ini mendesain 
spanduk dan banner adapun hasil kreativitas mereka di ukur oleh tim menggunakan tabel I. Hal ini tentu sangat menggembirakan bagi kami tim pengabdian masyarakat maupun peserta pelatihan dalam kegiatan ini.

Tabel I.Peserta dalam mengikuti kegiatan desain grafis

\begin{tabular}{|c|c|c|}
\hline $\begin{array}{c}\text { Penyampaian } \\
\text { Materi }\end{array}$ & $\begin{array}{c}\text { Persentasi } \\
\text { (\%) }\end{array}$ & Keterangan \\
\hline Materi & 10 & $\begin{array}{l}\text { Ketika pemamaparan } \\
\text { oleh tim pengabdian } \\
\text { peserta } \\
\text { mempu pelatihan } \\
\text { sebanyak } 10 \text { orang }\end{array}$ \\
\hline Inovatif & 20 & $\begin{array}{lr}\text { Dengan } & \text { melibatkan } \\
\text { peserta } & \text { untuk } \\
\text { pembuatan } & \text { desain } \\
\text { spanduk } & \text { mereka } \\
\text { langsung } & \text { membuat } \\
\text { desainnya } & \text { dengan } \\
\text { sangat menarik. } & \end{array}$ \\
\hline Kreatif & 50 & $\begin{array}{l}\text { Dalam pelaksanaan } \\
\text { pengabdian pada } \\
\text { masayarakat ini mucul } \\
\text { ide kreatif mereka } \\
\text { dalam melakukan } \\
\text { desain produk dan } \\
\text { mempromosikan karya } \\
\text { nya ke masyarakat. } \\
\text { Adapun Peserta } \\
\text { tersebut datang kepada } \\
\text { tim untuk menujukkan } \\
\text { karya nya kepada tim }\end{array}$ \\
\hline
\end{tabular}

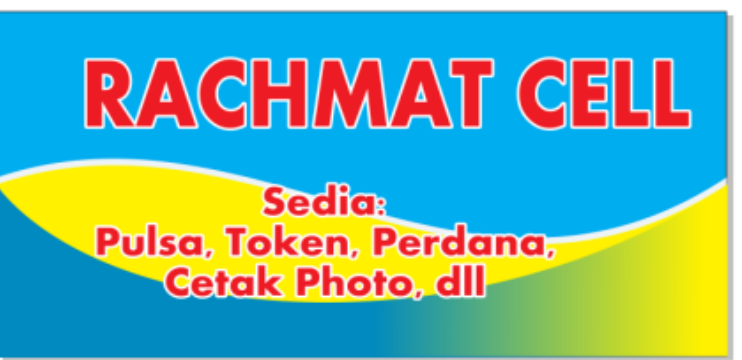

Gambar I. Materi tim Desain pengabdian

Gambar diatas merupakan pemaparan pembahasan materi yang telah disampaikan pada kegiatan pengabdian masyarakat dengan menguraikan beberapa point-point yang berhubungan dengan desain grafis. Adapun materi - materi yang telah dibahas dalam kegiatan tersebut antara lain :

I) Menjelaskan definisi dan manfaat dari desain grafis

2) Pengenalan software desain grafis

3) Melakukan praktek membuat dan mendesain spanduk dan banner

4) Menunjukkan hasil yang telah dipraktekkan

\section{KESIMPULAN}

Adapun beberapa kesimpulan yang dapat diambil dari kegiatan pelaksanaan pengabdian masyarakat tersebut, antara lain adalah :

a) Semangat Remaja Mesjid dalam mengikuti kegiatan pelatihan ini sangat tinggi sehingga mereka dapat memahami, mendesain dan membuat spanduk dan banner dengan cepat dan menarik,

b) Hampir $80 \%$ remaja mesjid sudah dapat memahami dan mendesain spanduk dan banner,

c) Kegiatan ini juga memberikan bekal ilmu dan gambaran terhadap remaja mesjid sehingga kelak dapat membuka usaha percetakan dan menambah penghasilan bagi remaja desa tersebut.

\section{UCAPAN TERIMA KASIH}

Tim mengucapkan terima kasih kepada pihakpihak yang telah berpartisipasi dalam kegiatan Pengabdian yang dilakukan. Terutama kepada kepala desa Seantis yang telah memberikan izin untuk dapat melaksanakan kegiatan ini dengan baik, dan terima kasih juga kepada remaja-remaja desa seantis untuk dapat meluangkan waktu saling berbagi ilmu dan meperaktekkan desain grafis bagi remaja desa agar dapat meningkatan kemampuan dalam mendesain spanduk dan banner. 


\section{REFERENSI}

Dewojati, R. K. W. (20I5) 'Desain Grafis Sebagai Media Ungkap Periklanan', Imaji, 7(2). doi: 10.21831/imaji.v7i2.6633.

Rahmat, S. T. (20/5) 'Pemanfaatan Multimedia Interaktif Berbasis Komputer Dalam Pembelajaran', Jurnal Pendiikan dan Kebudayaan Missio, 7(2), pp. 196-208.

Ryza, M., Spd, S. and Kom (2014) 'Berbasis Multimedia Interaktif, Jurnal Mahasiswa STEKOM Semarang, I(I). Available at: https://www.neliti.com/id/publications// 904 79/media-pembelajaran-desain-grafis-disma-I-kudus-berbasis-multimedia-interaktif. 